\title{
Analysis of shear wall buildings by the frame method
}

\section{A. MACLEOD}

\section{Dr T. C. Liauw, Department of Civil Engineering, University of Hong Kong}

The statements in $\S 3$ that many degrees of freedom in a space frame analysis can be neglected may require the qualification that the building is orthogonally symmetrical and the resultant loading passes through the centroidal axis of the building. If the structural plan is asymmetrical or if the resultant lateral loading does not pass through the centroidal axis, the structural elements are subjected to torsion, the effect ${ }^{19}$ of which may be significant and comparable to the bending effect.

27. In the analysis of tall buildings subjected to wind loading, it is important to realize that the seemingly rigid shear walls and core walls under bending are relatively weak against torsion because they are of thin rectangular section or thin walled open section.

28. The possibility of a tall building being subjected to torsion is high, even if the structure is orthogonally symmetrical. This is because turbulence is generated by wind around neighbouring buildings resulting in asymmetrical wind pressure and suction, especially when the wind direction is oblique to the axes of the building. ${ }^{20}$ Data collected from the full-scale experimental building at the High Building Research Centre in Hong Kong confirm similar phenomena although the building is situated in a relatively exposed location.

29. The stress distribution shown in Fig. 8 has not been verified by other more accurate methods or experimental data, and independent evidence seems to be required to show that a vertical load applied at the top of wall 1 will produce compressive stress in wall 5 of a magnitude of $87 \%$ of the stress in wall 1 , noting that the load must flow from wall 1 to wall 5 via two right-angled corners as shown in the key plan of the structure (Fig. 5).

\section{Dr MacLeod}

The main difficulty with torsional loading on tall buildings is not so much in the analysis as in estimating the intensity of the torsional loading.

31. The method described in the Paper can take account of torsion most satisfactorily. As an example Fig. 12(a) shows in plan a core shape. To analyse this, each face of the core is laid out as in Fig. 12(b) and a node freedom array (Table 4) is set up. This gives the vertical connexions at the wall junctions. At each floor level the walls must be constrained to move in a horizontal plane. The movement of such a plane can be defined by the horizontal movements of walls 1-2, 3-4 and 5-6, i.e. by freedoms 1, 6 and 10, to which freedom 14 must then be related. This relationship can be established using equilibrium. Defining $P_{t}$ as the force which corresponds to freedom $i$, for static equivalence

$$
\begin{aligned}
& \left\{\begin{array}{l}
P_{1} \\
P_{6} \\
P_{10}
\end{array}\right\}=\left[\begin{array}{c}
\sin \theta-a / L \\
-\cos \theta \\
-a / L
\end{array}\right]\left\{P_{14}\right\} \\
& \left\{P_{\mathrm{D}}\right\}=[A]^{\mathrm{T}}\left\{P_{\mathrm{R}}\right\}
\end{aligned}
$$

i.e. where $P_{\mathrm{D}}$ and $P_{\mathrm{R}}$ are the definitive and redundant actions respectively. ${ }^{4}$

32. The $A$ matrix can be used as described in reference 4 to eliminate freedom 14 effectively, and the analysis can proceed normally. 


\section{DISCUSSION}

33. This procedure neglects warping restraint but involves only 15 active degrees of freedom at each storey level. In order to carry out analysis of this problem as a conventional space structure one would probably have to use finite elements with a minimum of 20 nodes per storey giving possibly 120 degrees of freedom per storey. This would result in considerable data problems and excessive computer time, whereas the approach described here would be feasible on any reasonably big computer.

34. This procedure is therefore not limited to orthogonally symmetric problems and in fact can be used for almost any shear wall system. With respect to the redistribution of load indicated by Fig. 8 it would certainly be an interesting exercise

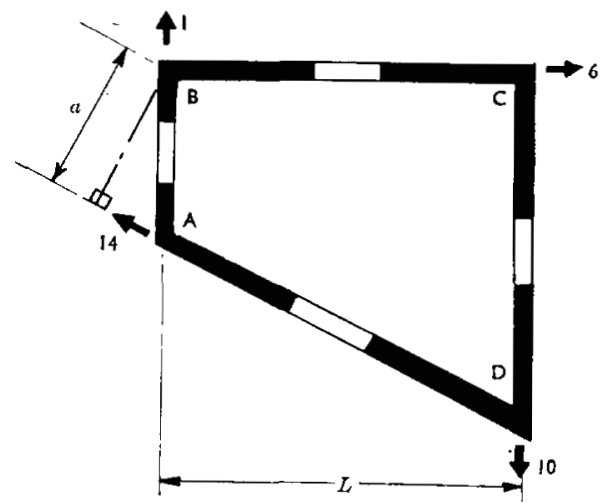

(a) Plan

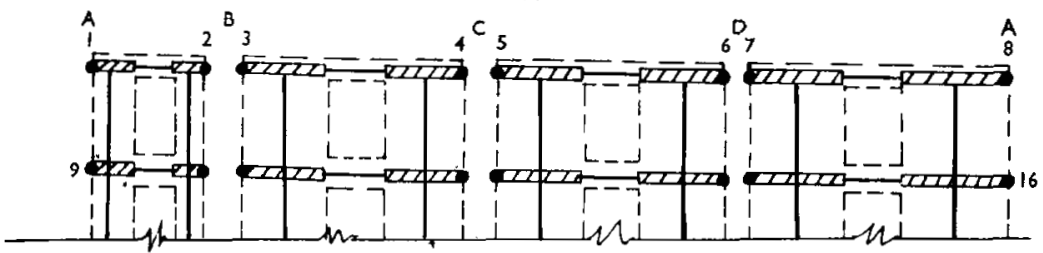

(b) Frame idealization

Fig. 12 Idealization of structural core

Table 4. Node freedom array for Fig. 12(b)

\begin{tabular}{c|c|c|c}
\hline Node & \multicolumn{3}{|c}{ Freedom numbers } \\
\hline 1 & 1 & 2 & 3 \\
2 & 1 & 4 & 5 \\
3 & 6 & 4 & 9 \\
4 & 6 & 8 & 11 \\
5 & 10 & 8 & 13 \\
6 & 10 & 12 & 15 \\
7 & 14 & 2 & 16 \\
8 & 14 & 18 &. \\
9 & 17 & $\cdot$ &. \\
. & $\cdot$ & $\cdot$ &. \\
\hline
\end{tabular}


to verify this experimentally. However, there is no doubt in my mind that a redistribution of this order would occur. I have many times compared the frame method with finite elements and with Perspex models and apart from localized problems I have invariably found satisfactory correlation for stress and deformation.

35. One difficulty with shear wall buildings is that they exhibit structural behaviour which is not familiar to designers. Most structural designers are accustomed to dealing with frames which are flexible such that a load applied at the top of the structure will not spread significantly across the structure and will go fairly directly to the nearest support. Shear wall buildings are normally rigid blocks where the foundation loading is governed more by the stiffness of the piles (if it is piled) than by the normal tributary approach for conventional frames.

36. The structure shown in Fig. 4 has rigid connecting beams between the openings and behaves rather as if it had no openings at all. Under these circumstances a fairly uniform distribution of foundation load is to be expected. If the loading were not symmetrical or the building were allowed to sway, then a non-uniform distribution would result. This distribution would tend to be a function of the stiffness of the foundation rather than of the structure. However, as can be seen from Fig. 8, a stage can be reached where the stiffness of the connecting beam does significantly affect the vertical load distribution.

\section{References}

19. Stafford Smith B. Analysis of tall core-supported structures subject to torsion. Proc. Instn Civ. Engrs, Part 2, 1972, 53, Dec., 173-187.

20. Dalgliesh W. A. Wind pressure measurements on full-scale buildings. Proceedings of the Chicago design symposium. Northwestern University, 1970, 89-107.

\section{Corrigenda}

Tables 1 and 2 of the Paper should read as follows.

Table 1. Node freedom array, lateral load

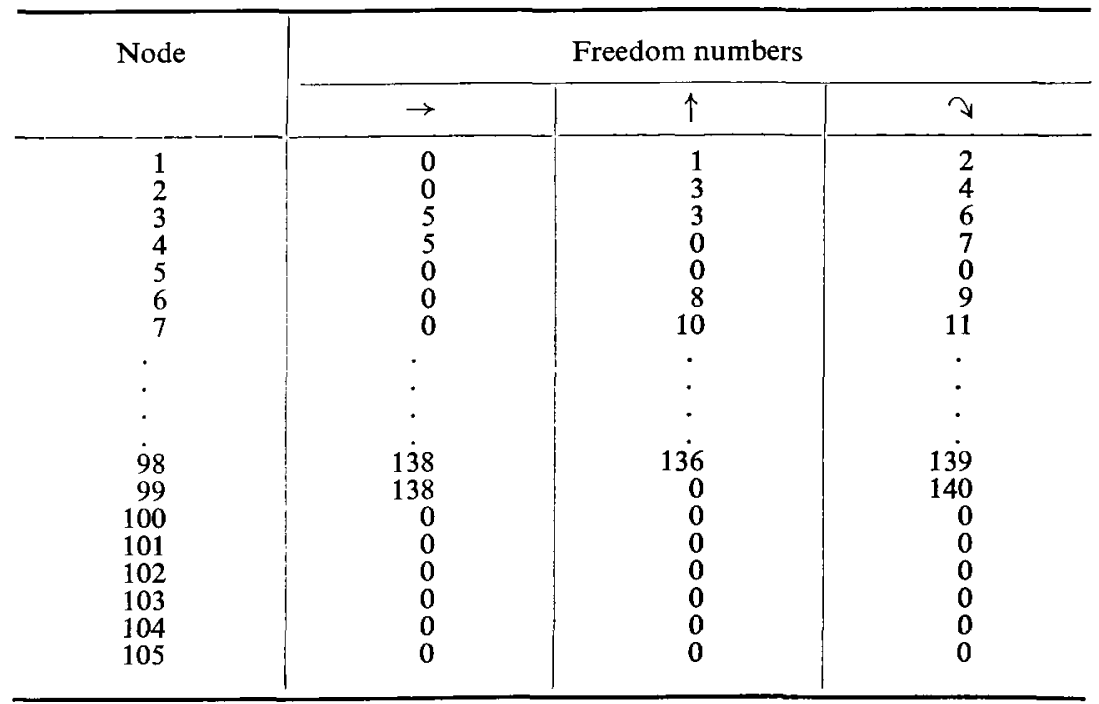


DISCUSSION

Table 2. Node freedom array, vertical load

\begin{tabular}{|c|c|c|c|}
\hline \multirow[t]{2}{*}{ Node } & \multicolumn{3}{|c|}{ Freedom numbers } \\
\hline & $\rightarrow$ & $\hat{\imath}$ & $\curvearrowright$ \\
\hline $\begin{array}{r}1 \\
2 \\
3 \\
4 \\
5 \\
6 \\
7 \\
. \\
. \\
. \\
. \\
99 \\
100 \\
101 \\
102 \\
103 \\
104 \\
105\end{array}$ & $\begin{array}{l}0 \\
0 \\
0 \\
0 \\
0 \\
0 \\
0 \\
. \\
. \\
. \\
\dot{0} \\
0 \\
0 \\
0 \\
0 \\
0 \\
0\end{array}$ & $\begin{array}{r}1 \\
3 \\
3 \\
6 \\
6 \\
8 \\
10 \\
\cdot \\
. \\
. \\
. \\
139 \\
139 \\
0 \\
0 \\
0 \\
0 \\
0\end{array}$ & $\begin{array}{r}2 \\
4 \\
5 \\
0 \\
7 \\
9 \\
11 \\
. \\
. \\
. \\
. \\
0 \\
140 \\
0 \\
0 \\
0 \\
0 \\
0\end{array}$ \\
\hline
\end{tabular}

